\title{
Mechanisms of Psychosocial Effects on Health: The Role of Social Integration, Coping Style anci Health Behavior
}

\author{
Julie M. Goldsmith Cwikel, PhD \\ Ted E. Dielman, PhD \\ John P. Kirscht, PhD \\ Barbara A. Israel, DrPH
}

To analyze the mechanisms by which psychosocial factors affect health, this research investigated social integration and indicators of coping style and their relation to health behaviors and health status. The analysis was conducted using the results of a 1977 survey of 854 household interviews from a multi-stage probability sample of adult residents of Washtenaw County, Michigan. Physical-health status was evaluated by two indices: Self-rated global health and self reports of chronic disability. Mental health was assessed with the Center for Epidemiologic Studies Depression Scale. Overall, the effects of the psychosocial factors were stronger for mental health than physical health. Social integration was shown to have direct effects on both physical and mental-health status. Internal locus of control was associated with lower levels of depressive symptoms. Chronic conditions were primarily affected by age, sex, and health behavior. Evidence from the path analyses suggested that part of the health benefit that women accrue from social integration and an active coping style is related to better health behavior. This mediation effect was not found for men.

The authors acknowledge the invaluable advice of James S. House and John R. Goldsmith.

This research was supported, in part, by Grant No. 502013 from the National Center for Health Services Research and Grant No. 28094 from the National Heart, Lung, and Blood Institute.

Julie M. Goldsmith Cwikel, $\mathrm{PhD}$, is a research associate with the Institute of Gerontology and Adult Human Development, Jerusalem, Israel.

Ted E. Dieman, $\mathrm{PhD}$, is a professor in the Department of Postgraduate Medicine and Health Professions Education, University of Michigan Medical School, and the Department of Health Behavior and Health Education, University of Michigan School of Public Health.

John P. Kirscht, PhD, is a professor of Health Behavior and Health Education, University of Michigan School of Public Health.

Barbara A. Israel is an assistant professor of Health Behavior and Health Education, University of Michigan School of Public Health.

Address requests for reprints to T. E. Dielman, $\mathrm{PhD}$, Department of Postgraduate Medicine and Health Professions Education, G1210 Towsley, University of Michigan Medical School, Ann Arbor, MI 48109-0201. 


\section{INTRODUCTION}

The resurgence of interest during the mid-1970s in the relationship between social ties and health status has resulted in an impressive volume of research into the relationship between social support and both specific health problems and overall health status. However, there remain many areas where the findings are either equivocal or where there is a lack of consensus about the meanings of key terms. ${ }^{1-4}$

The current state of knowledge indicates a need to investigate the relationship between social ties and health using multiple determinants and models that more closely approximate the presumed theoretical frameworks. Social support derived from the social ties that integrate and sustain functioning in society is but one type of psychosocial asset or resource with the potential for sustaining healthy functioning. To obtain a clearer understanding of how social ties affect health. related constructs such as general coping style and specific health-related coping behaviors need to be examined.

In a review of the epidemiological evidence concerning the link between social support and health, Broadhead and his colleagues ${ }^{5}$ showed that there is a paucity of conclusive evidence concerning the mechanisms by which social ties affect health. House ${ }^{6}$ outlined four ways through which social support may affect health: (1) through a direct effect; (2) as a buffer or moderator of adverse health outcomes caused by stress; (3) by reducing exposure to stress or health hazards; and (4) by facilitating recovery from health problems. The first two are the major conceptual pathways proposed to explain how social ties affect health. i.e., viewing social support as a main, direct effect or as a buffer or moderator in the stress-illness relationship. ${ }^{7-9}$ This investigation explores the hypothesized direct effects.

There have been several suggestions as to how direct mechanisms operate. Pilisuk ${ }^{10}$ proposed a general biological effect on the body's immune system which must be ascertained through basic, clinical research (see Broadhead, et al. ${ }^{5}$ for a review of some of this evidence). Berkman and Syme, ${ }^{11}$ in discussing their findings that the level of social and community ties was inversely related to mortality, proposed two pathways for direct effects. One proposal was that social ties affect health through health behavior, as socially integrated persons take better care of their health and socially isolated persons take more health risks. The second mechanism proposed was that social ties encourage more successful coping styles. A more active, problem-focused coping style has been shown to be more effective in dealing with stress than avoidance and withdrawal. ${ }^{12.13}$ Successful coping contributes to an overall sense of social competence or self esteem, which in turn may positively affect health.

Bandura $^{14}$ has hypothesized that the initiation of coping behavior specifically related to health is influenced by the perception of the benefits of taking preventive or curative action. Such perceptions of the benefits of taking specific actions to prevent disease are related to feelings of being in control of one's health and to an overall sense of personal competence. ${ }^{15}$

The purpose of this study was to estimate the direct effects of psychosocial factors and health behaviors on indices of physical and mental health, with demographic variables controlled. These direct effects were examined in relation to indicators of both physical and mental health in order to highlight the different mechanisms affecting mental health status and physical health status. Furthermore, using causal modeling, the direct effects of the psychosocial variables were contrasted with their indirect effects, as mediated by positive and preventive health behaviors, in order to test alternative assumptions specified in the hypothesized causal model. 


\section{CAUSAL MODEL}

A path model was constructed on the basis of prior theoretical and empirical work in order to represent alternative mechanisms for psychosocial effects on health. In addition to mediating and direct effects, the causal model, shown in Figure 1, also includes the indirect effects of background variables such as age. sex and education on health status, as mediated through psychosocial factors. This allows for the examination of the psychosocial factors, while controlling for the effects of age and education. Sex-specific path analyses were estimated since men and women have been shown to differ on many types of health behaviors and indicators of health status. ${ }^{16}$

\section{Exogenous (Control) Variables}

Two exogenous, demographic variables, age and education, were included in the model to reduce the likelihood that the observed relationships may be spurious. Age and education have been shown to be associated with positive health practices ${ }^{17}$ and with preventive health behaviors, ${ }^{18,19}$ so that those who are older and have more education are more likely to have better health behaviors. Older age is also more likely to be associated with poorer health status, as measured by self-report measures and by mortality statistics. ${ }^{20.21}$

\section{Psychosocial Factors}

Social ties have long been viewed as relevant to health status, but recent longitudinal studies have demonstrated the relationship between diverse sources of social relations and disease-specific outcomes such as angina pectoris. ${ }^{22}$ steroid dependence in adult asthmatics, ${ }^{23}$ and all-cause mortality in both general populations ${ }^{1,24}$ and in the elderly. ${ }^{25}$ Similar patterns of association have been observed for the relationship between social ties and mental health status. Although cross-sectional data have shown the beneficial effect of social ties on depression in a general population and in persons over 63 years of age, ${ }^{26.27}$ a direct amelioratory effect on psychological distress has also been demonstrated using a prospective, cohort design. ${ }^{28,29}$

One issue that has been cited by many investigators is the lack of a comprehensive framework to conceptualize and measure social ties. House and Kahn, ${ }^{30}$ in their overview, differentiated between three types of measures that have been used to operationalize social ties as they relate to health and well-being. These types are: (1) the quantity or existence of certain social relations, specifically the number of social contacts or the existence of certain kinds of social relationship, such as marriage or membership in organizations and here referred to as social integration; (2) the structure among an individual's social ties or the social network; and (3) the substance or quality of the social relationship or social support. The first type of measure entails enumerating various types of social ties, which have been found to be relatively stable over time, rendering this type of measure suitable for general population surveys. ${ }^{31}$ This is the type of measure used in this study.

Of the various types of social ties, the most intimate appear to have the strongest effects on health status. Married persons have been shown to have lower rates of 


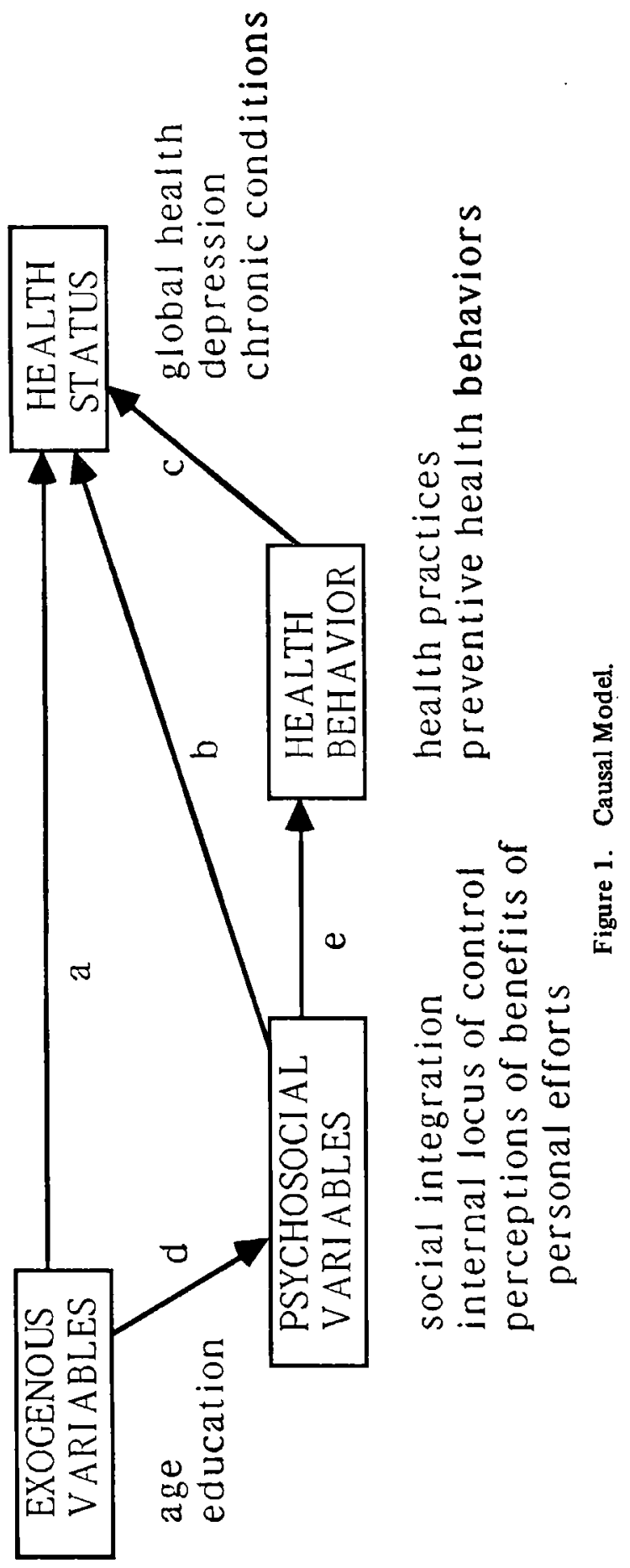


mental illness, ${ }^{32,33}$ lower mortality rates, ${ }^{34}$ and lower levels of chronic limitations and disability ${ }^{35}$ than unmarried persons. Despite the evidence concerning the benefits of marriage for health, some studies have suggested that the quality and the happiness of the marriage may be more consequential. ${ }^{32,36}$ Involvement in organized activity, such as membership in voluntary organizations, and religious and political participation have also been found to be correlated with health status, although the relationships are somewhat smaller than ties of marriage, friends, and relatives. ${ }^{11,24,31}$ In studies of frequent churchgoers, less reported illness and lower blood pressure levels were observed when compared to infrequent attenders. ${ }^{37,38}$

Perceptions of the benefits of personal action in relation to illness are postulated as being central attributes in helping people succeed in efforts to improve their health, for example, in quitting smoking or losing weight. ${ }^{39,40}$ Thus, perceptions of the benefits of personal action are part of an individual's overall perception of health and may be important in the initiation and maintenance of health behaviors.

Originally formulated by Rotter, ${ }^{41}$ the concept of locus of control proposes that those with a stronger sense of internal influence are more likely to engage in actions that prevent adverse outcomes. This may be due to the fact that those with a more internal locus of control have a more active approach to coping with problems. Husaini and $\mathrm{Neff}^{42}$ showed, for example, that the relationship between social class and depressive symptoms is attenuated when locus of control is considered. Similarly, Krause and Stryker ${ }^{43}$ found that men with moderate levels of internal locus of control cope more effectively with job stress and exhibit less psycho-physiological distress than either those who are extremely internal or moderately external.

\section{Health Behavior}

As defined by Kasl and Cobb ${ }^{44}$ health behavior is "any activity undertaken by a person believing himself to be healthy, for the purpose of preventing disease or detecting it in an asymptomatic stage" (p. 246). Behaviors that are health promotive, such as sleep, exercise, and nutritional practices, are most often referred to as health practices, after the work of Belloc and Breslow. ${ }^{45,46}$ They showed that seven positive health practices involving sleep; diet, weight, low levels of alcohol consumption, and abstinence from smoking were related to health status and mortality. In the current investigation, a differentiation was made between preventive health behaviors (e.g. health checkups, dental care and immunizations) and health practices (e.g., sleep, diet, exercise, and alcohol and cigarette use).

The idea that relations with the social environment affect one's health-related behavior was first articulated by Suchman. ${ }^{47}$ Building on Suchman's model, Langlie ${ }^{19}$ found that socially isolated people engaged in fewer behaviors such as immunizations, dental care, medical checkups, screening exams, seatbelt use, nutrition, and exercise that mitigate indirect health risk. Coburn and $\mathrm{Pope}^{18}$ also found that an index of social participation predicted the likelihoou of obtaining health exams, dental checkups and polio vaccines. In both studies ${ }^{18,19}$ preventive health behavior was positively associated with socioeconomic status and education.

Gottlieb and Green ${ }^{17}$ found that social ties were positively related to four health practices (never smoking, exercise, desirable weight, and sleeping 7-8 hours a night). 
Those who were older and had higher levels of education were more likely to engage in these health practices.

\section{Health Status}

Many of these psychosocial factors have been examined in relation to either physical or mental health status. In the current study psychosocial factors were examined in relation to several health status indicators, including both mental and physical health status. While depression and physical health status have been shown to be related to each other. ${ }^{48}$ an investigation of the relative effects of psychosocial factors on both types of indicators can enrich the understanding of how physical health and mental health status interact.

As Figure 1 indicates, several mechanisms of psychosocial effects were examined within a model approximating the hypothesized interrelationships. Thus, initially the relative direct effects of each set of variables on health status were examined: (1) the exogenous control variables (age, education, and sex); (2) the psychosocial variables, including social integration, internal locus of control, and perceptions of the benefits of personal action; and (3) indicators of health behavior, including positive health practices and preventive health behaviors. These direct effects correspond to pathways $a, b$, and $c$ in Figure 1. The causal model also permitted indirect pathways to be examined, and of particular interest was whether psychosocial variables had a direct effect on health status or whether the effect was mediated by health behavior. The indirect effect of psychosocial factors on health corresponds to paths e and $\mathrm{c}$ in Figure 1. The indirect effects of the exogenous variables through psychosocial factors were also examined by means of paths $d, b$ and $d, e, c$.

\section{METHODS}

\section{Sample}

Utilizing a multistage probability sample of adult residents of Washtenaw County, Michigan, data were collected as a part of a health survey conducted in 1977. Of the total number of households contacted. $10.5 \%$ were classified as not eligible because nonresident students were screened out of the sample. Of the eligible remaining households, $13.2 \%$ were nonresponse situations (house vacant, address not a housing unit or the enumerated respondent was absent), and $9.8 \%$ refused to be interviewed.

The resulting sample included 854 respondents, 368 males and 486 females. The sample ages ranged from 18 - 76 years, with $4.9 \%$ age 20 and under; $28.7 \%$ between the ages of 21 and $29 ; 35.8 \%$ between 30 and $39 ; 19.2 \%$ between 40 and 64 , and $11.0 \%$ over age 65 . Of the respondents, $19.7 \%$ had less than 11 years of education; $25 \%$ finished high school; $33.5 \%$ had some college education; and $20.7 \%$ had graduated from college. The respondents in the sample consisted of $91.4 \%$ white, $7.8 \%$ black, and $0.7 \%$ other ethnic categories. A majority of the sample were married and living with their spouse $(58 \%) ; 3 \%$ were separated, $10 \%$ were divorced, $6 \%$ widowed, $20 \%$ had never been married and $3 \%$ were single but living with a partner. The modal level of 
family income was over $\$ 25,000$ a year, although $42 \%$ earned less than $\$ 15,000$ a year. Since income and education were positively correlated in this sample $(r=0.28)$. and in a series of preliminary regression analyses income made no significant independent contribution to the variance accounted for in the dependent variables of interest after education entered the prediction equation, it was decided that only education would be used to control for socioeconomic level. This sample is representative of the residents of Washtenaw County, Michigan at the time the data were collected. A comparison of the distributions of the sample demographic variables with national census data during the same period revealed that the sample was somewhat higher with respect to levels of education and income. ${ }^{49}$

\section{Dependent Measures}

The dependent measures of interest were three measures of health status; (1) the Center for Epidemiologic Studies Depression Scale (CES-D); (2) the Global Health Rating; and (3) a Chronic Disability Index. All three were self report measures. The CES-D scale was developed by the Center for Epidemiological Studies for use in community surveys and has been validated as a measure of depressive symptoms rather than an indicator of a clinical diagnosis of depression. ${ }^{50}$ The CES-D scale consists of 20 items concerning the frequency of feelings in the past few months, with responses ranging over a five-point scale from hardly ever to always. Examples of these items include: "I was bothered by things that don't usually bother me;" "I had trouble keeping my mind on what I was doing;" and "I was happy." There were eight missing data cases on the CES-D index.

The Global Health Rating scale was a single item on which respondents compared themselves to other people their age. The responses ranged from $1-9$. where I indicated very poor health and 9 indicated excellent health. The Chronic Disability Index was made up of conditions mentioned by respondents in response to questions about health problems that hampered work ability or physical activity or that prompted physician visits. A count was made for each time any one of 50 possible chronic or recurrent conditions was mentioned. Each code was counted only once, so that the scores represented the actual number of conditions. There was one missing data case on the Global Health scale and none on the Chronic Disability Index. Further information on the formation of the Chronic Disability Index is found in Dielman, et al. ${ }^{49.51}$ Preliminary analyses indicated that weighting for the severity of the disability did not result in significant changes in correlations with the predictor variables.

\section{Exogenous Control Variables}

Education was represented by the number of years of formal education completed. Age was measured in years. In the multiple regression analyses, sex was coded 0 for men and 1 for women, so that a negative coefficient indicated higher levels for men and a positive coefficient indicated higher levels for women. None of the cases were missing data on these items. 


\section{Psychosocial Variables}

A Social Integration Index was formed based on the Social Network Index of Berkman and Syme. ${ }^{11}$ It combined four sources of social contact: being married, amount of social contact. church attendance, and activity in political and social organizations. The marriage variable was dichotomous (married or living with a partner versus never married. divorced, widowed, or separated). The amount of social contact was the respondent's estimate of the number of social contacts plus the number of those contacts seen at least once a month. The church or synagogue attendance variable was coded from 1 (never) through 4 (at least once a week). The political and organizational activity during the past year variable was coded from 1 (no activity) through 4 (very active). These variables were added to form the Social Integration Index score, with missing data assigned $(N=4)$ when the respondent had missing data on more than two of the component variables. The correlations among the component variables ranged from $0.07-0.26$. Additional details of the Social Integration Index can be found in Cwikel. $^{52}$

Two indices, Internal Control and Luck Denial were used to represent the propensity to control one's health and other events, also referred to in this article as "active coping style." The manner in which these two indices were formulated was determined by the results of an exploratory factor analysis, the details of which can be found in Cwikel. ${ }^{52}$ The Internal Control index was formed by summing responses (on four-point agree-versus-disagree scales) to three items concerning whether one can prevent illness from happening, whether one can prevent serious illness, and whether what happens to one is more a result of luck or one's own efforts. The Luck Denial index was formed by summing responses on a four-point agree-disagree scale to three items concerning whether one's health is a matter of luck, whether one might as well make decisions by flipping a coin, and whether it is wise to plan ahead. There were four missing data cases on the Internal Control index and five on the Luck Denial index. In the analyses reported here, scoring of the Luck Denial index was reversed so that it was positively related to the Internal Control index. Alpha coefficients for these indices were 0.57 for Luck Denial and 0.59 for Internal Control.

Two measures of the perceived benefits of personal efforts to prevent and treat disease, Benefits of Prevention and Benefits of Treatment, were additive indices formed from the number of positive responses to two questions: "Could ( $x$ disease) be prevented by a person's own efforts?" and "If a person had ( $x$ disease), could they reduce its danger through their own efforts?" These two questions were asked about a range of physical and mental problems: heart disease, stroke, hypertension, lung cancer, venereal disease, serious emotional problems, diabetes, arthritis, and dental problems. Missing data scores were assigned for these two indices when more than four of the constituent items had missing data codes. Otherwise the index scores were calculated by summing the number of items with valid scores and dividing by the number of those items. The Benefits of Prevention index had 33 missing data cases and the Benefits of Treatment index had 24. Alpha coefficients for these indices were 0.72 for Benefits of Prevention and 0.71 for Benefits of Treatment.

\section{Behavior Variables}

Two indices were constructed to represent two specific realms in health behavior. The first corresponds to the Health Practices Index used by Belloc and Breslow, ${ }^{45}$ 
except that a measure of the respondents' weight was not included. This health practices index assigned one point for each positive health practice reported by the respondent regarding current sleep patterns, alcohol consumption. cigarette smoking, exercise, snacking, and eating breakfast. The scores ranged from 0 (no positive health habits) to 6 (all 6 habits). A missing data code was assigned when more than three items were missing data $(N=1)$. The second index was a measure of preventive health behaviors which assigned one point for each preventive health behavior reported, including health checkups, immunizations, brushing and flossing teeth, and wearing seat belts. The time frame for reports of health behaviors was the six month period preceding the interview. Scores ranged from a high of 5 to a low of 0 . Missing data codes were assigned when more than two items were missing data $(N=6)$. The variables employed in the study are summarized in Table 1.

\section{Missing Data}

As noted in the preceding paragraphs, there were at most eight missing-data cases (less than $1 \%$ of the sample) for all indices except Benefits of Prevention, on which there were 33 missing-data cases (4\% of the sample) and Benefits of Treatment, on which 24 cases were missing data (3\% of the sample). The missing-data cases overlapped on some indices, and there were a total of 804 cases ( $94 \%$ of the sample) on which valid data were available on all variables for use in the regression and path analyses.

\section{Analysis}

After bivariate correlations were examined, a series of multiple regression equations were calculated to determine the relative weight of each set of variables in explaining the variance in the three dependent variables. This was done in an hierarchical fashion. entering the demographic variables first, then combinations of the demographic and psychosocial or health-behavior variables, and finally a full model which included all variables.

Because sex of the respondent was a significant predictor of Chronic Disability and Depression, sex-specific path analyses were conducted to examine the consequences of assuming the causal-path model discussed above. Although path analysis can not be used to test hypotheses directly, it can be used to model the appropriateness of the hypothesized causal structure. It allows direct and indirect pathways between predictor and dependent variables to be compared. The path coefficients are equivalent to standardized beta coefficients and represent the proportion of the standard deviation of the dependent variable which is affected in a direct way by the predictor variable while all other variables in the path diagram act through their specified pathways. The usual multiple-regression results reflect a path model where all the independent variables are assumed to have a bidirectional relationship with one another and a unidirectional relationship to the dependent variable. ${ }^{53.54}$ 
Table 1. Description of Variables.

Variable name

Variable description

A. Dependent variables

1. Center for Epidemiological Studies depression (CES-D) scale

\section{Global health rating}

3. Chronic disability index

B. Control variables

1. Age in years

2. Gender

3. Years of formal education

C. Predictor variables

1. Psychosocial variables

a. Social integration index

\section{b. Internal control index}

c. Luck denial index

d. Benefits of prevention index

e. Benefits of treatment index
A 20-item (five-point scale) self-report index of depressive symptomatology

A 9-point, single-item, self-rating of overall health

A count of the number of chronic conditions mentioned

\section{Self-explanatory}

$0=$ male, $1=$ female

Coded 0 to 17 -plus

An index which combined four sources of social contact: married/living with a partner $=1$ versus divorced, separated, widowed, or never married $=0$; Number of social contacts plus those seen at least once a month; frequency of church/synagogue attendance (Coded $1=$ never through $4=$ at least once a week), and a self-report of political/organizational activity (Coded $1=$ none through $4=$ very active).

A sum of three four-point, agree-disagree scale items concerning whether one can prevent illness from happening, whether one could prevent serious illness, and whether what happens to one is more a result of luck or one's own efforts

A sum of three four-point, agree-disagree scale items concerning whether one's health is a matter of luck, whether decisions might as well be made by flipping a coin, and whether it is wise to plan ahead

A sum of nine four-point agree-disagree items concerning whether, through one's own efforts, a list of diseases could be prevented (heart disease, stroke, hypertension, lung cancer, venereal disease, serious emotional problems, diabetes, arthritis, and dental problems)

A sum of nine four-point, agree-disagree items concerning whether the same diseases could have their danger reduced through treatment. 
Table 1. Description of Variables (continued)

Variable name
Variable description
2. Behavior variables

a. Health practices index

b. Preventive health behavior index
A sum of the number of positive health practices reported (sleep 7-8 hours a night, moderate or no alcohol consumption, no smoking, regular exercise, no snacking, regular breakfast)

A sum of the number of preventive health behaviors reported (regular health checkups, immunizations, regular tooth brushing, regular flossing, and wearing of seat belts)

\section{RESULTS}

\section{Bivariate Correlations}

The sex-specific bivariate correlations among all the variables, together with their means and standard deviations are shown in Table 2. Notable were the positive correlations between education and perceptions of benefits of personal efforts and health behaviors and the inverse relationship between age and education. The global health rating was strongly and negatively associated with the chronic disability and the depression indices. The depression and the -chronic disability indices were positively related.

\section{Multiple Regression Analyses*}

\section{Global Health Rating}

The global health rating was a subjective measure of health and the results show that a combination of demographic, psychosocial, and behavioral measures were significant predictors of these ratings of health. Higher levels of education and younger age were significant predictors $(p<0.01)$, together explaining approximately $9 \%$ of the variance. There was no direct effect of sex on the global health ratings. Of the psychosocial variables, the social integration index positively predicted global health $(\mathrm{p}<0.01)$ as did indicators of an active coping style, as evidenced by significant, positive coefficients for luck denial $(p<0.05)$ and internal control $(p<0.01)$. There were no direct effects of either measure of the perceived benefits of personal efforts in relation to health. When the global health rating was regressed on both the demographic and psychosocial variables, luck denial ceased to be a significant predictor, although both social integration and internal control remained significant predictors $(p<0.01)$.

* The tabular results of the series of multiple regression analyses which tested hierarchical models to explain the variance in health status are available upon request. These results will be described briefly here to allow comparisons with the results of the path analyses. 


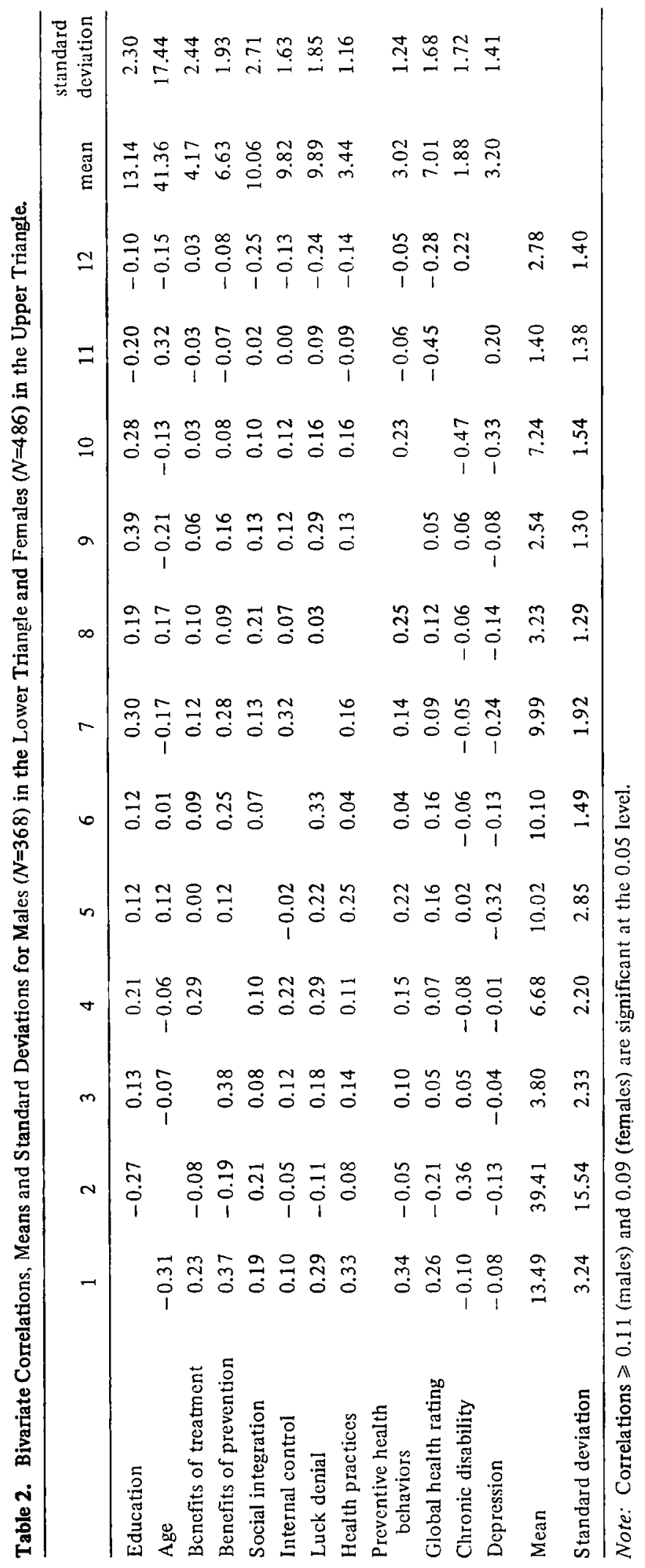


In testing the model that included both demographic and preventive health variables, the health practices index was shown to be a significant predictor $(p<0.01)$, while the preventive health behavior index was not. When the model combined the psychosocial variables and the preventive health behavior indices, both preventive health behavior $(p<0.05)$ and health practices $(p<0.01)$ affected the global health rating. As the bivariate correlations in Table 2 showed, education was significantly associated with both health practices $(r=0.33)$ and preventive health behavior $(r=$ 0.34 ) for men. For women, education was more strongly associated with preventive health behavior $(r=0.39)$ than health practices $(r=0.19)$. For women. age was positively correlated with positive health practices $(r=0.17)$, while age was negatively associated with preventive health behaviors $(r=-0.21)$. This helps explain why the index of preventive health behavior was not a significant predictor of the global health rating in the presence of education, age and sex.

All of the predictors in combination explained $11.8 \%$ of the variance in the global health index, with the largest single portion explained by the demographic variables, and the psychosocial and preventive health behavior indices together explaining approximately $6 \%$. The demographic variables shared some variance with indicators of coping style and preventive health behavior.

\section{Chronic Disability}

In predicting the level of chronic disability, by far the most significant predictors were the demographic variables. Those who were older, female, and less well educated were more likely to report chronic disability. These variables alone explained $14 \%$ of the variance in reports of chronic disability. Of the psychosocial variables, only the perception of the benefits of personal preventive efforts was significantly associated $(p<0.05)$ with less chronic disability. Health behavior explained a small $(1.5 \%)$ but significant proportion of the variance in chronic disability independent of the variance accounted for by the demographic variables. Those who practiced fewer positive health habits $(p<0.001)$ and who reported more preventive health behaviors $(p<$ 0.05 ) were more likely to report more chronic conditions. An examination of the bivariate correlations between the elements of the positive health behaviors index and chronic conditions showed that this positive correlation could be explained by the significant correlation of the physician checkups and chronic disability $(r=0.19)$. Correlations of other items in this index with chronic conditions did not reach significance. The finding that positive health practices correlated negatively with chronic conditions while positive health behaviors correlated positively with chronic conditions indicates that chronically ill respondents tend to be characterized by fewer positive health practices (moderate alcohol consumption, regular sleep and exercise, abstinence from smoking, etc.) and more visits to the physician. The psychosocial and health behavior indices alone explained only $2 \%$ of the variance, whereas combined with the demographic variables, $16 \%$ of the variance in chronic disability was explained.

\section{Depression}

Demographic variables were significant predictors of level of depression, explaining approximately $6 \%$ of the variance. Those who were young, female, and who had less 
education were more likely to indicate higher levels of depressive symptoms. The psychosocial variables also explained $13 \%$ of the variance in depression. Those who reported fewer positive health practices were also more likely to be depressed ( $p<$ $0.05)$. Those who were more socially integrated $(p<0.001)$ and possessed a more active coping style $(p<0.05)$ were less likely to be depressed. In the full model only age, sex, social integration, and luck denial remained as significant predictors, indicating that health practices. internal control, and education all shared some variance with other variables in the full model.

\section{Path Analyses}

The results of the sex-specific path analyses are found in Tables 3.4, and 5, which show the path coefficients for global health ratings. chronic disability, and depression. respectively. The tables also show the zero-order correlation coefficients that were used as input for the path analyses. Path analysis divides the correlation coefficient into direct effects, the indirect effects describing the portion of the variance accounted for through the pathways designated in the path model (see Figure 1). and the indirect but noncausal paths (which are not shown for ease of interpretation).

In this path model, it is possible to compare the direct effects of selected psychosocial variables on health status indicators with their indirect effects as mediated through the health behavior indices. In the case of the exogenous variables, age and education, the indirect effects were hypothesized to be through both the psychosocial and health behavior variables. Since age and education were significantly correlated, their correlation was entered in the path analyses. The health behavior indices were hypothesized to have only direct effects on the health status measure. In the path analyses. the index representing perception of benefits of personal action in relation to treatment was excluded because it had no significant zero-order correlations with the health status variables.

For descriptive purposes, the amount of variance explained by the path model was compared to the amount of variance explained by the sex-specific, regular multiple regression analyses, using the same variables.

\section{Global Health}

As Table 3 shows. the effect of education was similar for men and women with the direct effect several times larger than the indirect effect. Age appeared to affect global health rating differently for men and women. For men there was a negative direct effect $(-0.198)$. That is, older men tended to rate their health somewhat more poorly than younger men but the indirect effect through the psychosocial variables and health behavior was positive (0.05), indicating that age tended to have a positive effect on the global health rating through a combination of psychosocial factors and health behavior. For women there was practically no indirect effect of age (0.009) but the direct effect $(-0.069)$, though smaller than the direct effect of age for men. also was negatively associated with the global health rating.

In examining the indirect effects of the psychosocial variables, a clear difference between men and women appeared. For men, there were no indirect effects larger than 
Table 3. Path Coefficients for Males and Females (Shown in Parentheses) Relating Exogenous, Psychosocial and Health Behavior Variables to Global Health Rating: Comparison of Direct Effects with Indirect Effects Mediated through Health Behaviors

\begin{tabular}{|c|c|c|c|}
\hline & $\begin{array}{l}\text { Zero-order } \\
\text { correlation }\end{array}$ & $\begin{array}{l}\text { Direct path } \\
\text { coefficient }\end{array}$ & $\begin{array}{l}\text { Indirect } \\
\text { effects }\end{array}$ \\
\hline \multicolumn{4}{|l|}{ Exogenous variables } \\
\hline Age & $-0.215(-0.129)$ & $-0.198(-0.069)$ & $0.050(0.009)$ \\
\hline Education & $0.264(0.275)$ & $0.167(0.207)$ & $0.051(0.052)$ \\
\hline \multicolumn{4}{|l|}{ Psychosocial variables } \\
\hline Social integration & $0.164(0.099)$ & $0.160(0.030)$ & $0.012(0.048)$ \\
\hline Internal control & $0.160(0.123)$ & $0.130(0.069)$ & $0.002(0.026)$ \\
\hline Luck denial & $0.094(0.161)$ & $0.008(0.031)$ & $0.007(0.050)$ \\
\hline Benefits of prevention & $0.075(0.082)$ & $0.042(-0.008)$ & $0.003(0.034)$ \\
\hline \multicolumn{4}{|l|}{ Health behavior } \\
\hline Health practices & $0.122(0.163)$ & $0.063(0.132)$ & N.A.* \\
\hline \multicolumn{4}{|l|}{ Preventive health } \\
\hline behavior & $0.047(0.228)$ & $0.014(0.170)$ & N.A. \\
\hline \multicolumn{4}{|l|}{$\begin{array}{l}\text { Explained variance by } \\
\text { path analysis }\end{array}$} \\
\hline Global health $\quad R^{2}=0$ & $139(0.142)$ & & \\
\hline \multicolumn{4}{|l|}{$\begin{array}{l}\text { Explained variance by } \\
\text { regular regression }\end{array}$} \\
\hline
\end{tabular}

* Not Applicable

0.012, an indication that the psychosocial factors had largely direct effects on globalhealth ratings. For women, the psychosocial factors apparently were mediated to some degree by health behavior. since in three out of four cases the indirect effects were larger than the direct effects. The path analysis explained more variance for women than the regular regression, which is an indication that this path model. which includes the mediating effects of health behavior on the relationship between the psychosocial factors and global health ratings. is preferable in describing the observed relationships.

\section{Chronic Disability}

The results of the sex-specific path analyses for chronic disability are shown in Table 4. Age affected chronic disability similarly for men and women since there were large. direct effects in both cases and no indirect effects of any magnitude. Education had a zero-order negative correlation with chronic disability for men, but the direct effect was positive while the indirect effect was negative. There were no indirect effects of the psychosocial variables. all coefficients being quite close to zero. The only psychosocial variable with a direct effect of any magnitude was social integration, particularly for men. Those men who had lower levels of social integration reported 
Table 4. Path Coefficients for Males and Females (Shown in Parentheses) Relating Exogenous, Psychosocial and Health Behavior Variables to Chronic Disability: Comparison of Direct Effects with Indirect Effects Mediated through Health Behaviors

\begin{tabular}{|c|c|c|c|}
\hline & $\begin{array}{l}\text { Zero-order } \\
\text { correlation }\end{array}$ & $\begin{array}{l}\text { Direct path } \\
\text { coefficient }\end{array}$ & $\begin{array}{l}\text { Indirect } \\
\text { effects }\end{array}$ \\
\hline \multicolumn{4}{|l|}{ Exogenous variables } \\
\hline Age & $0.361(0.322)$ & $0.382(0.288)$ & $-0.018(0.000)$ \\
\hline Education & $-0.102(-0.204)$ & $0.042(-0.119)$ & $-0.032(-0.008)$ \\
\hline \multicolumn{4}{|l|}{ Psychosocial variables } \\
\hline Social integration & $0.016(0.019)$ & $-0.073(0.022)$ & $0.004(-0.021)$ \\
\hline Internal control & $-0.056(-0.002)$ & $-0.038(-0.002)$ & $0.001(-0.008)$ \\
\hline Luck denial & $-0.051(-0.091)$ & $-0.018(-0.002)$ & $0.002(-0.008)$ \\
\hline Benefits of prevention & $-0.079(-0.073)$ & $-0.020(-0.018)$ & $0.006(-0.011)$ \\
\hline \multicolumn{4}{|l|}{ Health behavior } \\
\hline Health practices & $-0.057(-0.089)$ & $-0.050(-0.088)$ & N.A.* \\
\hline Preventive health & & & \\
\hline behavior & $0.058(-0.058)$ & $0.078(-0.027)$ & N.A. \\
\hline \multicolumn{4}{|l|}{ Explained variance by } \\
\hline Chronic disability & \multicolumn{3}{|c|}{$\mathrm{R}^{2}=0.144(0.128)$} \\
\hline \multicolumn{4}{|l|}{$\begin{array}{l}\text { Explained variance by } \\
\text { regular regression }\end{array}$} \\
\hline Chronic disability & $=0.154(0.139)$ & & \\
\hline
\end{tabular}

* Not Applicable

more chronic conditions. Similar amounts of variance were explained by the path analysis and the regular regression.

\section{Depression}

The path coefficients for men and women with respect to the depression index are shown in Table 5. Age had both direct and indirect negative effects on depression for men. For women the effect of age was only a direct one. The largest effects of education were the indirect effects, indicating that education level did not directly affect depression for either sex, but that education acted through the psychosocial and health behavior variables. The psychosocial factors had only direct effects on depression and were not mediated through the health behavior indices. Both social integration and indicators of active coping style had negative effects on level of depression. Perceptions of the benefits of prevention appeared to be related to depression in the case of females. The path analysis explained more variance for both men and women than did the regular regression. 
Table 5. Path Coefficients for Males and Females (Shown in Parentheses) Relating Exogenous, Psychosocial and Health Behavior Variables to Depression: Comparison of Direct Effects with Indirect Effects Mediated through Health Behaviors

\begin{tabular}{|c|c|c|c|}
\hline & $\begin{array}{l}\text { Zero-order } \\
\text { correlation }\end{array}$ & $\begin{array}{l}\text { Direct path } \\
\text { coefficient }\end{array}$ & $\begin{array}{l}\text { Indirect } \\
\text { effects }\end{array}$ \\
\hline \multicolumn{4}{|l|}{ Exogenous variables } \\
\hline Age & $-0.127(-0.151)$ & $-0.086(-0.174)$ & $-0.081(-0.015)$ \\
\hline Education & $-0.078(-0.095)$ & $0.033(-0.012)$ & $-0.163(-0.133)$ \\
\hline \multicolumn{4}{|l|}{ Psychosocial variables } \\
\hline Social integration & $-0.328(-0.251)$ & $-0.304(-0.214)$ & $0.000(-0.006)$ \\
\hline Internal control & $-0.127(-0.128)$ & $-0.125(-0.114)$ & $0.000(0.003)$ \\
\hline Luck denial & $-0.242(-0.241)$ & $-0.243(-0.274)$ & $0.000(0.020)$ \\
\hline Benefits of prevention & $-0.009(-0.078)$ & $0.006(-0.067)$ & $0.001(0.004)$ \\
\hline \multicolumn{4}{|l|}{ Health behavior } \\
\hline Health practices & $-0.136(-0.141)$ & $-0.019(-0.074)$ & N.A. ${ }^{*}$ \\
\hline $\begin{array}{l}\text { Preventive health } \\
\text { behavior }\end{array}$ & $0.080(-0.052)$ & $0.024(0.078)$ & N.A. \\
\hline Explained variance by & $3(0.173)$ & & \\
\hline \multicolumn{4}{|l|}{$\begin{array}{l}\text { Explained variance by } \\
\text { regular regression }\end{array}$} \\
\hline
\end{tabular}

* Not Applicable

\section{DISCUSSION}

These data have three general limitations for evaluating health status: They are self report measures; they are representative of Washtenaw County, Michigan; and they are cross-sectional in nature. The first limitation affects the reliability and validity of responses; the second limits their generalizability; and the third affects the certainty with which causal attributions can be made. The self report measures used in this study have all been validated in prior research. The reliability and validity of self reports of chronic disabilities were tested in a special survey that replicated the self report questions on health status and compared them with very comprehensive health records at an HMO. ${ }^{55}$ The results of this study showed that the data were particularly reliable with respect to chronic illness. Although weighting chronic conditions for severity of disability did not result in significant changes in correlations with the predictor variables in this study, it is possible that such weighting would have an effect in a study in which the more severe disabilities were oversampled in a deliberate attempt to study this relationship. This was not the purpose of the present study. The relationships observed in this study may not be generalizable to the extent that residents of 
Washtenaw County differ with respect to the distribution of scores on and pattern of interrelationships among the variables studied. The nature of the causal attributions made in this paper are based on causal modeling techniques which stipulate that the causal model should be constructed on the basis of prior research. much of which was longitudinal. Thus. cross-sectional data are appropriate to test causal assumptions which can be described on the basis of the quantitative, observed relationships in the data.

In terms of the relative importance of the independent variables in this study, the overall direct effects of social integration and indicators of active coping style were particularly pronounced in relation to depression. moderately important in relation to the global health rating. and minimal in their relationship to chronic conditions. In a complementary fashion. demographic variables such as education. age. and sex explained increasing amounts of variance in depression. global health, and chronic conditions. respectively. so that chronic conditions were primarily affected by the demographic variables.

These data reinforce other findings which have shown that depression is related to physical illness. ${ }^{56.57}$ It is not possible with these findings to conclude whether depression precedes physical illness. develops concurrently. or is a product of physical illness. However, in another study that used causal modeling to determine the relationship between depression and physical illness. the demographic variables of socioeconomic status. age, and sex were found to affect both physical illness and depression. ${ }^{57}$ In that study. physical illness was found to have a large effect which increased concurrent levels of depressive symptomology, while depression was found to have a smaller, fourmonth lagged effect which increased physical illness. The results of the analyses re. ported here are quite analogous regarding the effects of age. education, and sex on illness and depression. Integrating these findings leads to the proposition that the effects of social integration and active coping styles occur over time, first on depression and mental health status. then on subjective health status, and over time the effect on physical health status becomes apparent. These results suggest the potential benefits of health education interventions designed to increase social integration and active coping. Such interventions could appropriately be directed at and evaluated through mental health effects, even where the ultimate goal is to improve physical health status.

The path analyses results allow a more detailed examination of the various effects. The findings indicate that psychosocial factors apparently affect the subjective rating of health for men and women differently. For men there was some indication that with age, some combination of psychosocial processes yielded a more positive assessment of their own health. For older men, social integration did help them maintain a positive assessment of their health.

For women. on the other hand. some effects of both social integration and indicators of active coping style operated through better health practices and preventive health behaviors. Although the bivariate relationship between social integration and global health was small. indirect effects through health practices and preventive health behaviors accounted for half of the relationship. When socially integrated, it appears that women use some of that benefit to invest in taking better care of their health. Women who are highly integrated with their family and/or an extended social network may perceive that the smooth functioning of the social system depends on their good health. Since health practices have been related to mortality, this may be part of the 
mechanism that results in women's longer life expectancy. Based on this finding health education programs directed at improving the health practices and health behavior of women might have a greater effect if they are implemented in a way that builds upon and strengthens already existing social relationships.

The gender differences appeared in the global health rating, a measure that has been shown to be associated with mortality. In a longitudinal study of the institutionalized aged. global health ratings were predictive of mortality, even after confounding factors such as objective health status and age were controlled. ${ }^{58}$ In another study. globalhealth rating was found to be influenced by age (younger people reported better health). gender (men reported better health). and associated with both physical and psychological symptoms. ${ }^{20}$

As expected. reporting of chronic conditions was strongly correlated with age for both men and women. There were slight differences between men and women on educational effects. For women, education had a negative direct effect on the reporting of chronic conditions, while there were modest direct and indirect effects of education formen.

In the path analyses it appeared that. for men only, low levels of social integration were associated with reporting more chronic conditions. This is consistent with the finding that low levels of social ties have greater consequences for the health of men than women. ${ }^{30}$ One explanation for this is that social ties, and particularly ties of marriage. offer health benefits to men in excess of what they accord to women. ${ }^{24}$ Therefore, men who lack these ties and have low levels of social integration are at greater health risk, and thus may be a particularly appropriate population for interventions designed to create new social ties, e.g., mutual-help groups. It should be noted that in this study the marriage variable was dichotomous (married/living with partner versus never married, separated, widowed, or divorced) rather than representing the various categories. There were not enough cases in some of these categories for a more detailed analysis. A more detailed representation of marital status may serve to increase the variance accounted for in the dependent measures.

Mental health status appeared to be affected by different processes than physical health status. The relationship between age and mental health was in the opposite direction from the relationship between age and physical health status. That is, depression scores were higher among younger people than among older people. For women this relationship was a direct one but for men about half of the effect of age on depression was through the psychosocial factors and health behaviors. It seems that. particularly for younger men. low levels of social integration and a more external locus of control were associated with depression.

Education had an interesting effect on depression. It has been reported that depression is more prevalent among those with lower levels of education. ${ }^{42}$ The results of this study suggest that the effect of education on depression for both men and women is largely mediated by social integration and indicators of active coping style. It appears that education level may be related to personal and social resources which in turn may defend against adverse mental-health outcomes. ${ }^{59}$

Among personal resources that protect and maintain health, locus of control is of particular interest since it may be more easily amenable to intervention than level of education. ${ }^{60,61}$ Langer and Rodin, ${ }^{62}$ in a field study with institutionalized aged persons. showed that increasing the opportunities and expectations for controlling the environment had important consequences for health and feelings of well-being, as well 
as on mortality in a long-term follow-up. ${ }^{63}$ These findings have implications for the health educator in that programs designed to enhance the sense of personal control over events may prove valuable in alleviating subjective symptoms of situational depression and improving subjective (and hence, possibly, objective) health. Assessment of locus of control could also be useful in screening participants and evaluating the effects of intervention programs that deal with depression and overall health and wellbeing.

From a theoretical perspective the importance of internal control for depression is consistent with the concept of "learned helplessness" as an explanation for understanding depression. ${ }^{64}$ According to this explanation, expectations of being able to control the environment are learned as a result of successful attempts to affect events. When outcomes appear to be independent of efforts to control them, subsequent attempts are less effective. Eventually, attempts to control the environment are not made and depression may result.

The data indicate that health practices and preventive health behaviors are associated with different health outcomes and sometimes predict the same health measure in different directions. Better health practices significantly predicted positive global health rating and fewer chronic conditions. On the other hand, engaging in more preventive health behaviors was a significant predictor of higher levels of chronic conditions. Poor health practices, such as excessive alcohol consumption and cigarette smoking, contribute to chronic illness. It is also possible that people suffering from chronic illness may be unable to maintain good health practices, such as exercise. The negative relationship between chronic conditions and preventive health behaviors was due to the tendency for people suffering from chronic illness to visit their physician more frequently. Therefore, health practices and preventive health behaviors, as measured in this study, represented quite different dimensions.

The overall effect of perceptions of the benefits of personal action on health was not supported by these data. Perceptions of these benefits were related to health behavior and internal locus of control. Evidently, perceptions of the benefits of personal action are of prime importance when change is required in health behavior. as originally formulated by Bandura. ${ }^{14}$ This suggests another recommendation for health education practitioners in the area of behavior change. Perceptions of the benefits of personal action in relation to health should not be overlooked when planning behavior change programs.

In conclusion, this research offers several insights for further understanding the mechanisms by which psychosocial factors affect health. Social ties and indicators of active coping are more strongly related to mental health status, although their effects are also apparent in subjective health ratings. Integrating these findings with existing longitudinal results ${ }^{57}$ suggests that the effect of psychosocial factors on chronic conditions is cumulative over time through the effect of mental health status on physicalhealth status. The mediation effect of positive health behaviors and health practices was observed for women only, indicating that psychosocial factors may contribute to the greater propensity of women to take preventive health action, which may ultimately reduce morbidity and mortality related to chronic illnesses. 


\section{References}

1. Lin NR, Simeone, RS, Ensel WM and Kuc W: Social support, stressful life events and illness: A model and an empirical test, J. Health Soc. Beh., 20:108-119, 1979.

2. Kahn $\mathrm{R}$ and Antonucci A: Convoys over the life course: Attachment roles and social support. In Baltes and Brim, (eds.) Life Span Development and Behavior, Vol 3, New York, Academic Press, 1980

3. Thoits P: Conceptual, methodological and theoretical problems in studying social support as a buffer against life stress, J. Health Soc. Behav., 23:145-159, 1982.

4. Wallston B, Alagna S, DeVellis B and DeVellis R: Social support and physical health, Health Psychol., 2:367-391, 1983.

5. Broadhead W, Kaplan BH, James SA, Wagner EJ, Shoenbach VJ, Grimson R, Hayden S, Tibblin G and Gehlbach SH: The epidemiologic evidence for a relationship between social support and health, Am J Epidemiol, 117:521-537, 1983.

6. House JS: Work Stress and Social Support. Reading MA: Addison-Wesley, 1981.

7. Gottlieb B: Social Support Strategies: Guidelines for Mental Health Practice, Beverly Hills, CA: Sage Publications, 1983.

8. Heller K, Swindle RW: Social networks, perceived social support and coping with stress, in Felner RD, Jason LA, Moritsugu J, Farber SS (eds): Preventive Psychology: Theory, Research and Practice in Community Intervention. New York, Pergamon Press, 1983.

9. Moos RH and Mitchell RE: Social network resources and adaptation: A conceptual framework, in Wills TA (ed): Basic Processes in Helping Relationships. New York, Academic Press, 1982.

10. Pilisuk M: Delivery of social support, Am. J. Orthopsych, 52:20-31, 1982.

11. Berkman L and Syme L: Social networks, host resistance, and mortality: A nineyear follow-up study of Alameda County residents, $A m$ J. Epidemiol., 109:186204, 1979.

12. Billings $A$ and Moos $R$ : The role of coping responses and social resources in attenuating the stress of life events, J. Behav. Med., 4:139-157, 1981.

13. Pearlin L and Schooler C: The structure of coping, J. Health Soc. Behav., 19:221, 1978 .

14. Bandura A: Self-efficacy: Toward a unifying theory of behavior change, Psychol. Rev., 84:191-215, 1977.

15. Ockene J. Nuttall R, Benfari RC, Hurwitz I and Ockene IS: A psychosocial model of smoking cessation and maintenance of cessation, Prev. Med., 10:623-638, 1981.

16. Verbrugge L: Gender and health: An update on hypotheses and evidence, $J$. Health Soc. Behav., 26:156-182, 1985.

17. Gottlieb N, Green LW: Life events, social networks, life-style and health: An analysis of personal health practices and consequences, Health Educ. Q., 11:91-105, 1984.

18. Coburn D and Pope C: Socioeconomic status and preventive health behavior, J. Health Soc. Behav., 15:67-78, 1974.

19. Langlie J: Social networks, health beliefs and preventive health behavior, J. Health Soc. Behav., 18:244-260, 1977.

20. Murray J, Dunn G and Tarnopolsky A: Self-assessment of health: An exploration of the effects of physical and psychological symptoms, Psychol. Med., 12:371$378,1982$.

21. Kitagawa EM and Hauser PM: Differential Mortality in the United States: $A$ Study in Sociological Epidemiology, Cambridge: Harvard University Press, 1973. 
22. Medalie JH and Goldcourt U: Angina pectoris among 10,000 men, Am. J. Med., 60:910-921, 1976.

23. De Araujo G, van Arsdel P, Holmes $T$ and Dudley D: Life change, coping ability and chronic intrinsic asthma, J. Psychosom. Res., 17:359-363, 1973.

24. House $J$, Robbins $C$ and Metzner $H$ : The association of social relationships and activities with mortality: Prospective evidence from the Tecumseh Community Health Study, Am. J. Epidemiol., 116:123-140, 1982.

25. Blazer D: Social support and mortality in an elderly community population, $A m$. J. Epidemiol., 115:684-694, 1982.

26. Lowenthal $M$ and Haven $C$ : Interaction and adaptation: Intimacy as a critical variable, Am. Sociol. Rev., 33:20-30, 1968.

27. Brown GW, Harris T: Social Origins of Depression. London, Tavistock, 1978.

28. Holahan CJ and Moos RH: Social support and psychological distress: A longitudinal analysis, J. Abnorm. Psychol, 90:365-370, 1981.

29. Turner R: Social support as a contingency in psychological well-being, $J$. Health Soc. Behav., 22:357-367, 1981.

30. House $\mathbf{J}$ and Kahn R: Measures and concepts of social support, in Cohen S. Syme L (eds): Social Support and Health, New York, Academic Press, 1985.

31. Donald C and Ware $\mathrm{J}$ : The Quantification of Social Contacts and Resources, Rand Gorporation, 1982.

32. Gove WR: The relationship between sex roles, marital status and mental illness, Social Forces, 51:34-44, 1972.

33. Gove W. Huges $M$ and Style $C$ : Does marriage have positive effects on the psychological well-being of the individual?, J. Health Soc. Behav., 24:122-131, 1983.

34. Kraus $A$ and Lilienfeld A: Some epidemiological aspects of high mortality in the young widowed group, J. Chron. Cis., 10:207-217, 1959.

35. Verbrugge L: Marital Status and Health, J. Marriage Family, 5:267-285, 1979.

36. Renne KS: Health and marital experience in an urban population, J. Marriage Family, 34:338-350, 1971 .

37. Comstock GW and Partridge KB: Church attendance and health, J. Chronic Dis., $25: 665-672,1972$

38. Graham TW et al.: Frequency of church attendance and blood pressure elevation, J. Behav. Med., 1:37-44, 1978.

39. Condiotte $M$ and Lichenstein E: Self-efficacy and relapse in smoking cessation programs. J. Consult. Clin. Psychol., 49:648-658, 1981.

40. DiClemente C: Self-efficacy and smoking cessation maintenance: A preliminary report, Cognitive Therapy Res., 5:175-187, 1981.

41. Rotter J: Generalized expectancies for internal versus external control of reinforcement, Psychol. Monogr., 80:1-34, 1966.

42. Husaini BA and Neff JA: Social class and depressive symptomatology: The role of life change events and locus of control, J. Nerv. Ment. Dis., 169:638-647, 1981.

43. Krause $\mathrm{N}$ and Stryker S: Stress and well-being: The buffering role of locus of control beliefs, Soc. Sci. Med., 18:783-790, 1984.

44. Kasl S and Cobb S: Health behavior, illness behavior and sick role behavior, Arch. Environ. Health, 12:246-266, 1966.

45. Belloc NB and Breslow L: Relationship of physical health status and health practices, Prev. Med., 1:409-421, 1972.

46. Belloc NB: Relationship of health practices and mortality. Prev. Med., 3:125-135, 1973.

47. Suchman E: Sociomedical variations among ethnic groups, Am. J. Soc., 70:319$330,1964$. 
48. Magni G, Leo D and Grassetto M: Depression and physical illness, Psychother. Psychosomat., 36: 129-131, 1981.

49. Dielman $T$ and Leech S: Intrafamilial Correlations among Health Beliefs, Health Behavior and Health Status, Office of Educational Resources and Research, University of Michigan Medical School, 1981.

50. Radloff L: The CES-D Scale: A self-report depression scale for research in the general population, Appl. Psychol. Measurement, 1:385-401, 1977.

51. Dielman TE, Leech SL, Becker MH, Rosenstock IM, Horvath WJ and Radius S: Parental and child health beliefs and behavior, Health. Educ. Q., 9:60-77, 1982.

52. Cwikel JG: Pathway's of Psychosocial Effects on Health: The Role of Social Integration, Coping Style and Health Behavior. Unpublished doctoral dissertation, University of Michigan, School of Public Health, 1986.

53. Li CC: A Primer of Path Analysis, Pacific Grove, CA: Boxwood Press, 1975.

54. Asher H: Causal Modeling, Beverly Hills, CA, Sage Publications, 1983.

55. Meltzer JW and Hochstim JR: Reliability and validity of survey data on physical health, Pub. Health. Rep., 85:1075-1085, 1970.

56. Andrews G, Tennant C, Hewson D and Vaillant G: Life events stress, social support, coping style and the risk of psychological impairment, J. Nerv. Ment. Dis., 166:307-315, 1978 .

57. Aneshensel $C$, Frerichs $R$ and Huba $G$ : Depression and physical illness: A multiwave, nonrecursive causal model, J. Health Soc. Behav., 25:350-371, 1984.

58. Mossey $\mathrm{J}$ and Shapiro E: Self-rated health: A predictor of mortality among the elderly, Am. J. Public Health, 72:800-808, 1982.

59. Liem $\mathrm{R}$ and Liem $\mathrm{J}$ : Social class and mental illness reconsidered: The role of economic stress and social support, J. Health Soc. Behav., 19:139-156, 1978.

60. Wallston B and Wallston K: Locus of control and health: A review of the literature, Health Educ. Monogr., 6:107-117, 1978.

61. Seeman $M$ and Seeman T: Health behavior and personal autonomy: A longitudinal study of sense of control in illness, J. Health Soc. Behav., 24:144-160, 1983.

62. Langer EJ and Rodin J: The effects of choice and enhanced personal responsibility for the aged: A field experiment in an institutional setting, J. Pers. Soc. Psychol., 34:191-198, 1976.

63. Rodin $\mathrm{J}$ and Langer E: Long-term effects of a control-relevant intervention with the institutionalized aged, J. Pers. Soc. Psychol, 35:897-902, 1977.

64. Seligman M: Helplessness, San Francisco, Freeman, 1975. 